\title{
ADAPTAÇÃO INTERLINGUAL DE FÁBULA EM ANÁLISE: PROPOSTA METODOLÓGICA E ESTUDO DE CASO
}

\author{
INTER-LINGUAL ADAPTATION OF A FABLE IN ANALYSIS: \\ METHODOLOGICAL PROPOSAL AND CASE STUDY
}

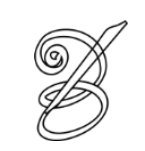

\author{
Clarissa ROSAS* \\ Universidade Federal da Paraíba, Brasil
}

\begin{abstract}
Resumo: O presente artigo insere-se em uma pesquisa maior acerca da descrição de retextualizações de fábulas de Tomás de Iriarte entre o espanhol e o português. Discute uma proposta metodológica para a análise de traduções e apresenta um estudo de caso sobre uma das fábulas de Iriarte, publicada na Espanha no século XVIII e traduzida ao português brasileiro no século XX. De modo a esquematizar alguns pontos para análise, apresenta-se o esquema de aplicação do referencial teórico adotado - o modelo descritivo de tradução proposto por Lambert e Van Gorp (2011 [1985]), complementado pelo trabalho de Genette (2009 [1987]) acerca dos paratextos editoriais, elementos que contribuem para a produção de sentido e orientam a recepção da obra traduzida. Em seguida, dá-se início ao estudo de caso, que analisa o texto-fonte "El Burro Flautista" e o texto-alvo "O Asno Flautista". A análise conclui que o texto-alvo tem como principal finalidade adequar-se ao público infantil. Para tanto, realiza adaptações que alcançam o texto de forma global, alterando a construção de sentidos em diversos aspectos. Em todos os níveis analisados, o texto-alvo tende para o polo da aceitabilidade e, por suas características dominantes, foi identificado não como uma tradução propriamente dita, mas como uma adaptação interlingual.
\end{abstract}

Palavras-chave: Literatura infantil. Paratextos editoriais. Tradução interlingual. Adaptação interlingual. Fábula.

Abstract: This article is part of a major research on the description of retextualizations of Tomas de Iriarte's fables from Spanish to Portuguese. It discusses a methodological proposal for the analysis of translations and presents a case study on one of Iriarte's fables, published in Spain in the eighteenth century and translated into Brazilian Portuguese in the twentieth century. In order to outline some points for analysis, we present the theoretical framework created by Lambert and Van Gorp (2011 [1985]) and the work of Genette (2009 [1987]) about editorial paratexts, elements that contribute to the production of meaning and guide the reception of translated texts. The case study analyzes the source text "El Burro Flautista" and the target text "O Asno Flautista". The analysis concludes that the main purpose of the target text is to meet the children as a target audience. In order to do so, it makes adaptations that reach the text in a global way, altering the construction of meanings in several aspects. At all levels, the target text tends towards the pole of acceptability and its dominant characteristics lead us to identify it not as a translation, but as an inter-lingual adaptation.

Keywords: Children's literature. Paratexts. Inter-lingual translation. Inter-lingual adaptation. Fable.

RECEBIDO EM: 28 de fevereiro de 2019

ACEITO EM: 28 de julho de 2019

PUBLICADO EM: janeiro 2020 


\section{Introdução}

$\mathrm{N}$

o século XVIII, foi publicada na Espanha a primeira compilação das fábulas de Tomás de Yriarte. Nascido em 1750 na ilha de Tenerife - uma das ilhas do arquipélago das Canárias, território espanhol situado a aproximadamente $300 \mathrm{~km}$ do continente africano -, Yriarte foi o autor de 76 fábulas em verso. Destas, 67 foram publicadas pela primeira vez em 1782, no livro intitulado Fábulas Literarias. Em nota à primeira edição desse livro, o editor o apresenta como a primeira coleção de fábulas inteiramente originais publicadas em castelhano. Em uma das reformas ortográficas pelas quais passou a língua espanhola provavelmente, a de 1815 -, seu nome passou a ser escrito Tomás de Iriarte, forma em que é grafado atualmente nos mundos lusófono e hispanófono. Em publicações mais antigas, como a de 1782, citada neste trabalho, seu nome ainda aparece grafado com Y.

As fábulas de Iriarte têm sido traduzidas ou adaptadas para diversos idiomas nos últimos séculos. Tiveram uma primeira tradução em Portugal ainda no século XVIII, em 1796 (14 anos após a publicação espanhola). Desde então, foram publicadas diversas outras vezes tanto em português europeu quanto brasileiro, em seu conjunto ou em seleção de algumas delas. Essas

52 publicações em português se relacionam de formas diferentes com os textos das fábulas de Iriarte: por exemplo, nem sempre estão também em verso e nem todas seguem linearmente o texto em espanhol.

Este artigo se propõe a analisar uma retextualização de uma das fábulas de Iriarte para o português brasileiro, realizada no século XX, descrevendo as diferentes operações do texto-alvo e procurando colocá-las em relação com diferentes nomenclaturas utilizadas para designar "ofertas informativas secundárias" (REISS \& VERMEER, 1996[1984], p. 14-15), ou textos que se derivam de outro texto que os antecede cronologicamente e visivelmente lhes serve como texto-fonte.

Tendo em conta o processo histórico de inserção do gênero fábula na literatura infantil (discutido anteriormente em Rosas (2016), (2017) e Rosas; Cintrão (2018)) e considerando que o propósito e o público-alvo de um texto de chegada parecem ser a chave para entendê-lo, o presente estudo pretende conjugar uma perspectiva descritiva e uma funcionalista para investigá-lo. Na próxima seção, apresentamos um esquema de aplicação do referencial teórico adotado para a análise.

\section{Referencial teórico de análise}

Partimos da hipótese de que serão encontradas diferenças de cunho linguístico atribuíveis ao distanciamento temporal entre a produção do texto-alvo e do texto-fonte, mas principalmente diferenças que se justifiquem no propósito da tradução e em seu público-alvo, 
observáveis inclusive em elementos paratextuais e estruturas narrativas. Para investigar tais pontos, consideramos apropriado o modelo descritivo de tradução literária desenvolvido por Lambert e Van Gorp (2011) em 1985, o qual se apoia na teoria dos polissistemas de Even-Zohar (1978) e Toury (1980).

O modelo propõe descrever e examinar as estratégias tradutórias em diferentes aspectos, considerando desde questões preliminares, como presença ou não do nome do tradutor e se a tradução é parcial ou completa, até aspectos de micronível, como seleção de palavras e padrões gramaticais. De forma complementar, o trabalho de Genette (2009[1987]) sobre os paratextos editoriais fornecerá subsídios para observar as chamadas “questões preliminares” do modelo de Lambert e Van Gorp, como elementos que contribuem para a produção de sentido e orientam a recepção da obra traduzida.

Começaremos descrevendo as questões preliminares, tendo em conta as características específicas de nosso próprio corpus. Devem ser observados os seguintes aspectos: quais são o lugar e ano de publicação e a editora? A edição constitui a obra completa (todas as fábulas) ou uma parte dela (uma ou algumas fábulas)? Faz parte de uma antologia de fábulas (traduzidas ou não)? Contém apenas fábulas de Iriarte ou também de outros autores e quais? Quais são as fábulas de Iriarte que inclui? Traz o texto em português ou em espanhol? Mantém-se o título da obra completa (Fábulas Literarias)? Há indicação de gênero (fábulas)? O nome do autor aparece? O nome do tradutor ou adaptador está indicado? É apresentada explicitamente como antologia, tradução, adaptação? Mantém-se a advertência do editor e outros metatextos? Tem ilustrações ou não e de que tipo?

Quanto ao macronível, os aspectos a observar devem ser: a fábula mantém a estruturação em versos ou foi transformada em prosa? Uma tradução prosaica específica de verso é compatível com a função da prosa no sistema-alvo? O texto da fábula é corrido ou fragmentado em várias páginas? Há manutenção dos diálogos? Numa primeira observação geral, seria tradução, adaptação, apropriação ou qual outra categoria e por quais características notáveis? Traz o texto completo, modificado, reduzido, ampliado? Tende para o polo da adequação ou da aceitabilidade e por quais características notáveis?

Com relação ao micronível, devem ser observados os seguintes aspectos: a relação (natureza da equivalência) que se vê com o texto-fonte é de lineariedade palavra por palavra, parágrafo por parágrafo, com o texto completo reproduzido por meio do método da típica tradução escrita, ou não? Não sendo, que tipo de relação se realiza? Há redução, acréscimo, alteração na forma de diálogos? Como estão organizados os elementos narrativos (personagens, tempo, espaço, diálogo, narrador, ações enredo)? O nível da linguagem é mantido? Os padrões 
gramaticais são semelhantes? Predomina o uso da ordem direta ou indireta? Como se percebem os níveis de coloquialidade? Como foram traduzidos alguns itens lexicais específicos? Que grau de humanização pode ser observado nas personagens, no caso de inserção de ilustrações? As adjetivações apontam para valoração mais ou menos explícita sobre as personagens e suas ações para o leitor (levando em conta o caráter moralizante das fábulas)? Deixa-se a dedução da moral e a valoração mais para o leitor, a partir da ação, ou ela é dada mais pronta e explícita ao leitor por elementos do próprio texto (além da sentença moral que apareça ao início ou ao final)?

Quanto ao contexto sistêmico, os aspectos a observar devem ser: como o texto se configura em relação ao gênero fábula, historicamente falando (considerando características gerais das fábulas, como pouca descrição, assentar-se essencialmente sobre uma ação que é muito fundamentada num diálogo no tempo presente, em uma só unidade de cena, com economia de personagens, personagens animais)? Como se configura em relação aos padrões literários de cada época, como o uso de versos na literatura (considerando que a forma poética foi durante muito tempo o modo de expressão literário por excelência, e era, portanto, frequente 54 que a produção literária ocorresse em verso)?

Essa análise deve levar a comentários finais sobre a categorização do texto-alvo enquanto tradução, adaptação, apropriação, etc; sobre técnicas adotadas, como redução, ampliação, mudança de gênero; e sobre o público-alvo declarado ou inferido a partir desse estudo (utilizando, para isso, a análise de paratextos proposta por Genette), em relação com o público de Iriarte e o sistema de origem de seus textos.

A seguir, apresentamos brevemente outras bases teóricas e conceituais relevantes para as análises de micronível, que serão consideradas em conjunto com a proposta de Lambert e Van Gorp e com o trabalho de Genette. Esse complemento diz respeito à consideração dos elementos básicos de textos narrativos (narrador, personagens, tempo, espaço, ação), por serem as fábulas um gênero essencialmente narrativo; a elementos de análise de textos em versos (como número de sílabas, estruturação em estrofes, estruturas de rimas), no caso do texto-fonte; e a procedimentos de tradução e de adaptação. São elas:

- Elementos básicos dos textos narrativos: por serem as fábulas um gênero essencialmente narrativo, julgamos necessário abordar durante a análise elementos como narrador, personagens, tempo, espaço, ação e enredo. Para tanto, adotaremos como referência o livro de Cândida Vilares Gancho (2002), Como analisar narrativas. 
- Elementos de análise de textos em versos: como o texto-fonte é versificado, será preciso analisar aspectos como número de sílabas, estruturação em estrofes e estruturas de rimas. Para isso, utilizaremos como referência o manual de Antonio Quilis (1975), Métrica española.

- Diferenciação entre tradução e adaptação: consideraremos na análise a diferenciação básica estabelecida por Georges Bastin (2009[1997]) entre adaptação local procedimento técnico presente em um grande número de traduções - e adaptação global - método de retextualização que, para sua definição, depende de uma concepção de tradução da qual se diferencia.

- Procedimentos técnicos de tradução: a fim de apontar as adaptações locais identificadas no texto-alvo durante a análise, levaremos em conta os procedimentos técnicos de tradução elencados por Jean-Paul Vinay e Jean Darbelnet (1958), como ampliação, redução, modificação, etc.

- Focos de adaptação na literatura infantil: teremos em mente, durante a análise - ainda que isso não seja explicitado na redação - os quatro focos de adaptação na literatura para crianças elencados por Göte Klinberg (1973 apud ZILBERMAN, 2003), que são assunto, forma, estilo e meio.

\section{Estudo de caso}

\subsection{O texto-fonte “El Burro Flautista” (1782)}

“El Burro Flautista” é a Fábula VIII do livro Fábulas Literarias (YRIARTE, 1782). Ocupa as páginas 19 e 20 da primeira edição do livro, publicada na Espanha. Esta edição contém 67 fábulas em verso, compostas como narrativas em forma de poemas, mas nenhuma delas incorpora aos textos das fábulas a sentença moral que acompanha edições mais modernas. A edição de 1782 apresenta tais sentenças morais separadamente, num índice de fábulas e seus assuntos. Não constam imagens no interior do livro nem na capa. Uma advertência do editor é o único paratexto que antecede o início das fábulas. O sumário, onde estão incluídas as sentenças morais, é apresentado logo após o final da última fábula. Esta primeira edição de 1782 foi consultada em fac-símile digitalizado ${ }^{1}$.

\section{a) Visão geral da composição}

Como todas as demais fábulas desse volume, trata-se de uma narrativa em forma de poema. Tem a participação de apenas uma personagem, nomeada no título: um burro. O texto tem 94 palavras (excetuado o título) e se caracteriza pela economia de recursos narrativos, 
condensando-se basicamente na narração da ação, numa única cena e uma só fala do burro. Dos seus 28 versos, 4 representam o monólogo do burro (vs. 21 a 24), enquanto 24 são ocupados pela voz narrativa, em primeira pessoa nos versos iniciais (1 a 4), que são metanarrativos (tematizam sua própria ação de narrar a fábula), passando à terceira pessoa no restante da fábula, da perspectiva de um narrador não participante e onisciente.

A voz narrativa identifica o espaço em que se desenrola a ação de forma imprecisa, em apenas dois versos, sem descrevê-lo (Cerca de unos prados | Que hai en mi Lugar). Introduz a personagem por meio de um substantivo comum iniciado com maiúscula e precedido de artigo indefinido (un Borriquito), sem nenhum adjetivo que o qualifique ou valore. Concentra-se na ação. Anuncia a fala da personagem com o verbo de dictum mais frequente e neutro (decir) e apresenta seu julgamento acerca da situação nos últimos versos, na forma de enunciação da moral da história. A distribuição dos elementos da narrativa pelas estrofes do texto pode ser esquematizada como segue no quadro 1. 
Quadro 1 - Fábula “El Burro Flautista” (1782)

\begin{tabular}{|c|c|c|c|c|}
\hline \multicolumn{5}{|c|}{$\begin{array}{c}\text { FÁBULA VIII } \\
\text { EL BURRO FLAUTISTA }\end{array}$} \\
\hline 1 & Esta fabulilla, & & \multirow{4}{*}{ 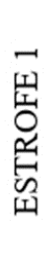 } & \multirow{4}{*}{ 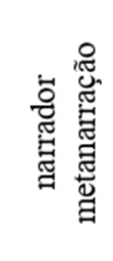 } \\
\hline 2 & Salga bien, ó mal, & A & & \\
\hline 3 & Me ha ocurrido ahora & & & \\
\hline 4 & Por casualidad. & A & & \\
\hline 5 & Cerca de unos prados & & \multirow{4}{*}{ 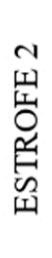 } & \multirow{2}{*}{ espaço } \\
\hline 6 & Que hai en mi Lugar & A & & \\
\hline 7 & Pasaba un Borrico & & & \multirow{14}{*}{ 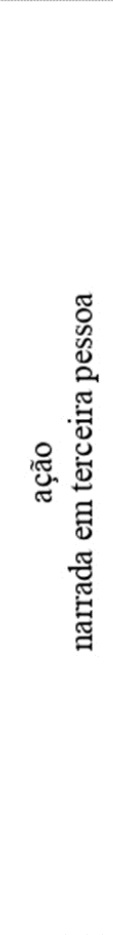 } \\
\hline 8 & Por casualidad. & A & & \\
\hline 9 & Una flauta en ellos & & \multirow{4}{*}{ 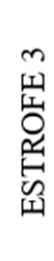 } & \\
\hline 10 & Halló, que un Zagal & A & & \\
\hline 11 & Se dexó olvidada & & & \\
\hline 12 & Por casualidad. & A & & \\
\hline 13 & Acercóse á olerla & & \multirow{4}{*}{ 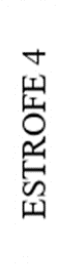 } & \\
\hline 14 & El dicho animal; & $\mathrm{A}$ & & \\
\hline 15 & Y dió un resoplido & & & \\
\hline 16 & Por casualidad. & A & & \\
\hline 17 & En la flauta el aire & & \multirow{4}{*}{$\begin{array}{l}n \\
\text { 至 } \\
0 \\
0 \\
\text { 告 } \\
\text { 至 }\end{array}$} & \\
\hline 18 & Se hubo de colar; & A & & \\
\hline 19 & Y sonó la flauta & & & \\
\hline 20 & Por casualidad. & $\mathrm{A}$ & & \\
\hline 21 & Oh! dixo el Borrico: & & \multirow{4}{*}{ 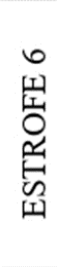 } & \multirow{4}{*}{ 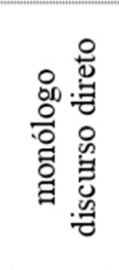 } \\
\hline 22 & ¡Qué bien sé tocar! & A & & \\
\hline 23 & Y dirán que es mala & & & \\
\hline 24 & La música asnal. & A & & \\
\hline 25 & Sin reglas del arte & & \multirow{4}{*}{ 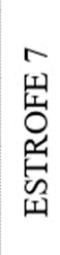 } & \multirow{4}{*}{ 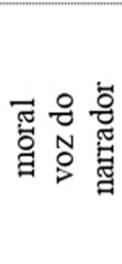 } \\
\hline 26 & Borriquitos hai & A & & \\
\hline 27 & Que una vez aciertan & & & \\
\hline 28 & Por casualidad. & A & & \\
\hline
\end{tabular}

Fonte: ROSAS, 2017, p. 106.

A sentença moral da Fábula VIII aparece à página 160, no “Índice de las fábulas y de sus asuntos", remetendo à página do texto da fábula no livro (imagem a seguir). $\mathrm{O}$ assunto 
apresentado apenas reitera a moral enunciada pelo narrador nos versos finais: "Sin reglas del arte |Borriquitos hai | Que una vez aciertan | Por casualidad'.

Figura 1 - Sentença moral da fábula "El Burro Flautista" (1782)

\section{FÁBula VIII. El Burro Flautista. \\ Sin reglas del arte, el que en algo acierta, acierta por casualidad. Pág.r 9.}

Fonte: YRIARTE, 1782 (p. 160).

\section{b) Forma poética}

A Fábula VIII - "El Burro Flautista" é uma das três indicadas na composição "Endechas de seis sílabas, ó versos de Redondilla menor", na página 174 da seção "Géneros de metro usados en estas fabulas" (imagem reproduzida a seguir).

Figura 1 - Métrica utilizada na fábula "El Burro Flautista" (1782)

\section{Endechas de seis silabas, ó versos de Redon- dilla menor. Fáb. VIII. XI. y XXXVI.}

Fonte: YRIARTE, 1782 (p. 174).

A endecha, segundo Moisés (2004, p. 142), foi desenvolvida na Espanha durante o século XVI e é geralmente composta de uma estrofe de quatro versos de cinco ou seis sílabas, com os seguintes esquemas rímicos: $\mathrm{ABCB}, \mathrm{ABAB}, \mathrm{ABBA}$. $\mathrm{O}$ poema formado por mais de uma estrofe recebe o nome de "endechas". As endechas de seis sílabas, também chamadas de versos de redondilla menor, diferem da tradicional redondilha menor portuguesa, que tem cinco sílabas (enquanto a redondilha maior tem sete). A redondilla menor espanhola é composta de uma métrica "menor" (menos de nove sílabas) e de origem popular, caracterizada por estrofes de quatro versos, versos de seis sílabas, rimas finais vocálicas entre os versos pares iniciadas pela última vogal tônica da palavra e número não fixo de estrofes.

A fábula VIII está disposta em vinte e oito versos de seis sílabas, com divisão em sete estrofes de quatro versos cada uma. A modo de exemplo, a divisão silábica nos primeiros dois versos seria: 
Es / ta / fa / bu / li / lla (6 sílabas)

$\mathrm{Sal} / \mathrm{ga} / \mathrm{bien} / o ́$ / $\mathrm{mal}(5+1=6 \text { sílabas })^{2}$

A partir da palavra casualidad, que se repete ao final do último verso de cada estrofe (com exceção da sexta estrofe, que termina com a palavra asnal), é feita a rima única em A, ao longo de todos os segundos versos de cada estrofe, do 2 ao 26: mal, Lugar, Zagal, animal, colar, tocar, hai. As rimas, portanto, acontecem em todos os versos pares.

Os acentos rítmicos não são regulares, contando com algumas variações ao longo dos versos. O início das estrofes aparece indicado tipograficamente por recuo de primeira linha no primeiro verso (com exceção da primeira estrofe, que começa alinhada). Quatro estrofes estão dispostas na página 19 e três, na página 20 - ao que tudo indica, por razões de espaço. Reproduzimos o texto no quadro 1 com a mesma ortografia e os mesmos espaçamentos, apenas acrescentando a numeração das estrofes e dos versos para facilitar a referência a cada um deles ao longo da análise.

Como recursos formais do texto poético, esta fábula se vale notavelmente de paralelismos estruturais nos versos finais de seis das sete estrofes - versos 4, 8, 12, 16, 20 e 28 -, repetindo a mesma estrutura compositiva (Por casualidad) e destacando sempre a casualidade de tudo o que aconteceu ao burro, o que coloca esse aspecto no centro da discussão, como vimos. Por meio da situação específica que o burro experimenta, está representada uma questão mais abrangente: as habilidades de um indivíduo, que devem ser consideradas como aquelas que podem ser repetidas com sucesso, e não aquelas que são realizadas bem uma única vez por pura sorte. E, sabendo que as fábulas de Iriarte têm aplicação especial na literatura, entendemos que a reflexão se aplica a escritores de uma obra única que obtiveram êxito, mas não voltaram a produzir.

\section{c) Elementos da narrativa}

A voz narrativa predomina na fábula, ocupando vinte e quatro dos vinte e oito versos. Começa por apresentar a fábula como uma história na qual o narrador pensou no momento, casualmente, sem grande esforço (v. 1 Esta fabulilla, [...] v. 3 Me ha ocurrido ahora | v. 4 Por casualidad), e, por isso, o narrador afirma que pode se sair bem ou não na composição (v. 2 Salga bien, ó $\mathrm{mal}$ ) - o que faz com que a fábula já inicie dando o tom da moral que defende e possibilita apresentar o verso que se repete ao final de quase todas as estrofes: Por casualidad.

Em seguida, a voz narrativa apresenta o espaço (v. 5 Cerca de unos prados | v. 6 Que hai en mi Lugar) e a única personagem (v. 7 Pasaba un Borrico). O espaço tem pouca 
funcionalidade para o enredo e não é retomado posteriormente, enquanto que a caracterização da personagem é mínima: não há nenhum elemento de descrição física para além de sua inserção numa categoria específica de animal, o que consiste na única informação a partir da qual os leitores podem inferir sua imagem recorrendo a seu conhecimento de mundo. Tampouco há qualquer caracterização psicológica explícita, quer seja na voz do narrador ou na do próprio burro. A caracterização do protagonista como ignorante fica implícita na dupla acepção da palavra "borrico": (1) "animal de los mas pacientes, serviciales y provechosos al hombre"; (2) “llaman tambien por desprecio á un ignorante" (TERREROS Y PANDO, 1786).

Figura 3 - Verbete "Borrico" no Dicionário Castellano de Terreros y Pando

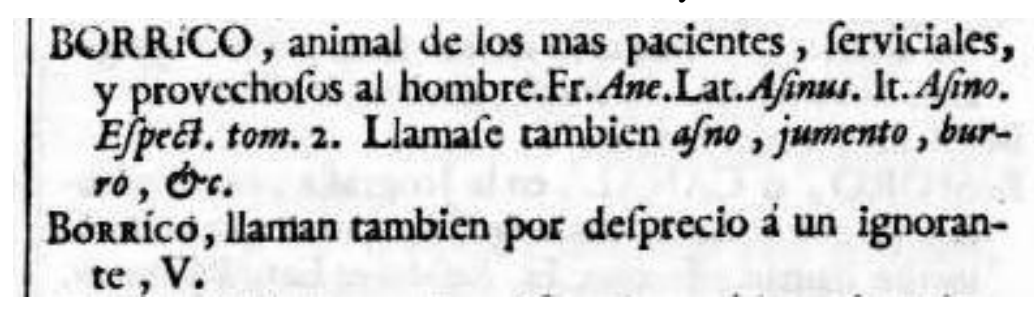

Fonte: TERREROS Y PANDO, 1786 (p. 263).

$\mathrm{O}$ autor faz com que o protagonista se apresente por seus próprios atos e coloca o leitor como testemunha direta da cena, descrevendo tudo o que acontece e mediando a única fala do burro com o verbo de dictum mais frequente e neutro (menos marcado) da língua espanhola: decir (v. 21 Oh! dixo el Borrico: | v. 22 ;Qué bien sé tocar!| v. 23 Y dirán que es mala | V. 24 La música asnal). Assim, a personagem se apresenta e se caracteriza psicologicamente sobretudo pela ação que desempenha na fábula, arrematada pelo julgamento do narrador na última estrofe (v. 25 Sin reglas del arte |v. 26 Borriquitos hai | v. 27 Que una vez aciertan | v. 28 Por casualidad). O verso 14, que explicita a personagem que executa a ação, não parece ser essencial e poderia ser suprimido sem prejuízos ao enredo; portanto, parece estar mais a serviço da organização formal em versos que da estrutura narrativa (v. 13 Acercóse á olerla|v. 14 El dicho animal; | v. 15 Y dió un resoplido).

Predominam os verbos no pretérito, que aparecem na voz do narrador: ha ocurrido, pasaba, halló, dexó olvidada, acercóse, dió, hubo, sonó e dixo. Os verbos no pretérito são usados no relato da cena, que transcorre num tempo passado indeterminado, e de modo geral indicam ações (passar, hallar, dejar, acercarse, dar e sonar). Os demais verbos adotados nesse momento são de natureza existencial (ocurrir) e verbal (decir). A voz narrativa retorna após a fala do burro, apresentando a moral da história com verbos no presente de natureza existencial 
(hai) e material (aciertan) - entendendo este último como "fazer algo bem". Ainda aparece um verbo no presente no começo da fábula, para apresentação do espaço (hai), e um verbo no subjuntivo, usado para introduzir uma ação possível, mas incerta: o êxito da fábula (salga).

$\mathrm{Na}$ fala do burro, há um verbo no presente, de natureza mental, que indica um conhecimento que o protagonista acredita ter (sé tocar), e um verbo no futuro, de natureza verbal, que indica o que o burro julga ser o discurso geral acerca da música produzida por asnos (dirán) - ou seja, não propriamente algo que acontecerá no porvir. Temos, assim, um texto em que narrador e personagem são os principais elementos narrativos, mas com grande predominância da voz narrativa, que é quem conta a história e apresenta um julgamento sobre ela.

Quanto ao léxico, observamos três formas de nomear o protagonista: Burro, no título; Borrico, no relato da história, com duas ocorrências; e Borriquito, na moral apresentada pelo narrador ao final da fábula. As variações Borrico e Borriquito não parecem atender a uma razão especial no campo da semântica, servindo mais à composição métrica dos versos (seis sílabas poéticas) que à composição narrativa.

Quanto aos níveis de linguagem, é especialmente notável a presença de arcaísmos ${ }^{3}$. O maior número de marcas se dá na acentuação: ó, á [olerla], dió (em lugar de $o$, a, dio). Duas são na grafia: hai (em lugar de hay) e dixo (em vez de dijo); uma na colocação pronominal acercóse (em lugar de se acercó). Talvez o uso de maiúscula em alguns substantivos também possa ser incluído nessa lista, posto que não acontece apenas com relação ao protagonista (Burro, Borrico) - o que se poderia interpretar como mais um recurso de humanização do animal, transformando o substantivo comum em nome próprio -, mas também se dá nos substantivos comuns Lugar e Zagal.

Identificadas as características dominantes do texto-fonte, passaremos a examinar o texto-alvo.

\subsection{O texto-alvo "O Asno Flautista" (s.d.)}

"O Asno Flautista” é a única fábula contida no livro homônimo (IRIARTE, s.d.). Ocupa as oito páginas do livro, publicado no Brasil. Pertence à edição em português brasileiro, publicada pela editora Villa Rica em Belo Horizonte, intitulada O Asno Flautista. Trata-se do volume 16 da coleção Fábulas do Mundo Todo, a qual inclui volumes que recolhem fábulas de La Fontaine, Samaniego, Esopo, Iriarte e Tolstoi, com uma única fábula por livro. $O$ Asno 
Flautista contém apenas a fábula que intitula a obra, em prosa. Não traz prefácio ou notas de qualquer natureza.

O texto apresenta-se distribuído em várias páginas, em letras graúdas e permeado de ilustrações. As imagens no interior do livro e na capa e suas características permitem presumir que o público-alvo dessas fábulas é o infantil. Trata-se de um livro ilustrado em formato vertical, cujas ilustrações têm função narrativa, reforçando as ações descritas no texto. Disponível em versão impressa. Não se apresenta como tradução ou adaptação, não constam os nomes do(a) tradutor(a)/adaptador(a) e do(a) ilustrador(a) nem o ano da publicação, mas aparenta ter sido editado na segunda metade do século XX (em levantamento bibliográfico realizado em ROSAS, 2017, foi identificada uma outra edição desse livro publicada em 1999).

\section{a) Visão geral da composição}

O texto-alvo configura-se como uma narrativa em forma de prosa. Apresenta a sentença moral incorporada ao texto, logo após o término da fábula, sem qualquer tipo de destaque que a diferencie do corpo do texto. Observa-se que a fábula cresce bastante, distribuindo-se em várias páginas. Como resultado, o texto-alvo tem 298 palavras (excetuado o título e incorporada a sentença moral) - quase o triplo do texto de partida, que tem 106 palavras (contando com a sentença moral, que não é apresentada junto ao texto; sem ela, são 94 palavras). Das 298 palavras do texto-alvo, 48 representam a fala do burro, enquanto 245 representam a voz narrativa. As demais palavras distribuem-se em outras vozes, acrescidas na retextualização: um ratinho amigo do burro, que faz uma exclamação de 2 palavras, e os concidadãos do burro, que fazem uma exclamação de 4 palavras. Na fábula de 1782, a fala do burro representa 13 das 94 palavras, enquanto o narrador dá conta das outras 81. Portanto, percebe-se, além da inserção de novas vozes, que tanto a voz do burro quanto a do narrador crescem: cada uma delas é triplicada.

A fábula distribui-se em oito páginas, que combinam texto e ilustração. O texto verbal é colocado acima e abaixo do texto visual, alternadamente, e cada um deles ocupa aproximadamente metade da página, com igual destaque. $\mathrm{O}$ texto visual reitera o verbal e tem função narrativa. As sete ilustrações aparecem livres nas páginas, sem margem ou moldura, são figurativas e mostram cenas do enredo, com cores vivas. As páginas 4 e 5 contam com uma ilustração única que ocupa toda a área central das páginas e é circundada por três blocos de texto verbal (ver figura 4). O formato do livro e a enunciação gráfica, que pode ser entendida 
como a forma do texto, são convencionais. O tipo de ilustração e as letras graúdas indicam claramente que o público-alvo dessas fábulas é o infantil.

Figura 4 - Diagramação da página em “O Asno Flautista” [s.d.]

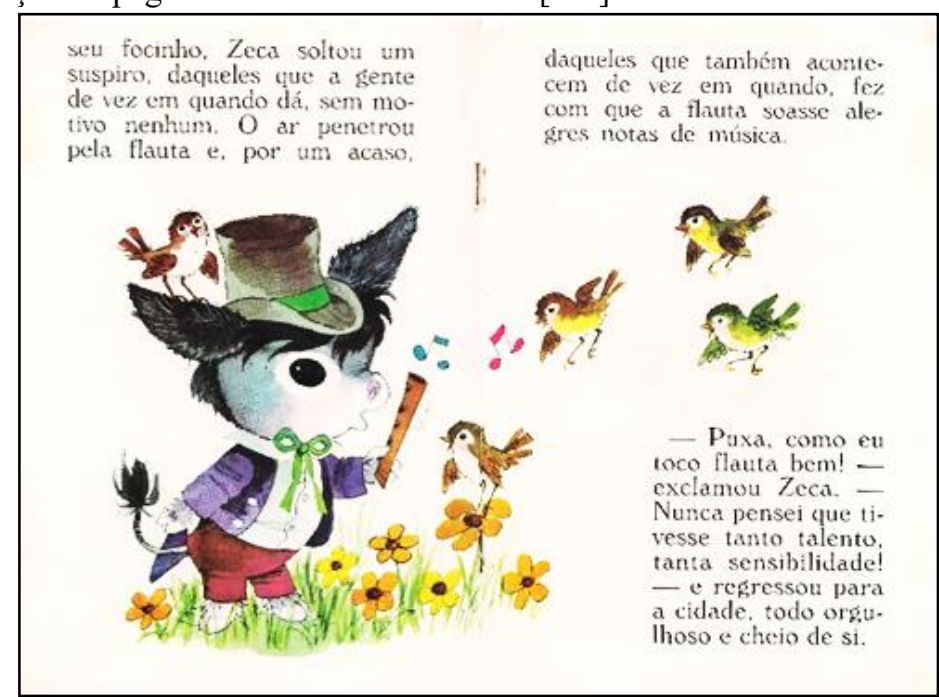

Fonte: IRIARTE, [s.d.] (p. 4-5).

Reproduzimos o texto integralmente no quadro 2.

Quadro 2 - Fábula “O Asno Flautista” [s.d.].

O ASNO FLAUTISTA
Zeca era um burrinho que vivia na saida da cidade, pertinho do bosque.
Todas as manhãs ele saia, bem cedinho, para fazer um pouco de exercicio.
Depois de tomar um café da manhã bem reforçado, Zeca resolveu colher
umas margaridas.
- Vou escolher as mais bonitas para enfeitar a minha casa - dizia alegre,
enquanto fazia o buquê.
Caminhando distraído, Zeca pisou em uma flauta que algum pastor havia
esquecido.
Dois passarinhos conversavam alegremente em cima da flauta, e seus
trinados eram tão suaves como se fossem música.
- Quem será que perdeu isso? - perguntou-se Zeca, ao ver a flauta.
Curioso, pegou a flauta do chão. Quando a aproximou de seu focinho, Zeca
soltou um suspiro, daqueles que a gente de vez em quando dá, sem motivo
nenhum O ar penetrou pela flauta e, por um acaso, daqueles que também
acontecem de vez em quando, fez com que a flauta soasse alegres notas de
música.
- Puxa, como eu toco flauta bem! - exclamou Zeca. — Nunca pensei
que tivesse tanto talento, tanta sensibilidade! — e regressou para a cidade,
todo orgulhoso e cheio de si.
No caminho, encontrou Tato, o ratinho seu amigo:
- Você já sabe que eu sou um grande músico? Esta manhã, no bosque,
toquei uma música lindissima na flauta!
- Que fantástico! - disse Tato, admirado.
E a noticia correu pela cidade. Ninguém havia ouvido Zeca tocar flauta,
mas como ele afirmava que era um gênio musical, todos acabaram se
convencendo:
- Temos um grande músico!
Vaidoso, Zeca mandou colocar uma placa bem em frente de sua casa: Zeca
Asno - Músico.
E assim viveu muito tempo, acreditando que sabia mesmo tocar flauta, sem
dar-se conta que fora apenas um acaso que fizera soar as notas aquela manhã
no bosque.
Quando por uma vez se acerta uma coisa, não quer dizer que saibamos fazê-
la bem.

Fonte: ROSAS, 2017, p. 128.

ROSAS, Clarissa. Adaptação interlingual de fábula em análise: proposta metodológica e estudo de caso. Belas Infiéis, Brasília, v. 9, n. 1, p. 51-71, 2020. 
É digno de nota que este volume pertence a uma coleção (Coleção Fábulas do Mundo Todo, da editora Villa Rica). Apesar de ser apenas uma fábula, o selo de uma coleção dá um novo contexto, ao colocar o texto lado a lado com fábulas de La Fontaine, Samaniego, Esopo e Tolstoi. Esse contexto é em parte comparável, talvez, com o de uma antologia, definida pelo dicionário Aulete como uma "coleção de textos (em prosa ou em verso) selecionados de forma que melhor representem a obra de um autor, ou um tema comum a vários autores, ou uma época etc". Como sinônimos, o dicionário apresenta os termos "coletânea" e "seleta". A Coleção Fábulas do Mundo Todo, a modo de antologia, representa um gênero comum a vários autores, com uma seleção feita de forma a melhor representar esse gênero. Assim, pode-se entender que a inserção em uma antologia de fábulas dá importância ao fabulário de Iriarte e, em especial, à fábula escolhida para representá-lo.

\section{b) Elementos da narrativa}

Os acréscimos no texto-alvo são notáveis e tornam o texto muito mais longo que a primeira edição espanhola (1782). Os acréscimos vão muito além do que seria imprescindível

64 a uma passagem de verso para prosa - que, no caso de uma retextualização interlingual, como esta, não teria que ser considerada necessariamente como uma adaptação, já que se pode traduzir um texto versificado em prosa e ainda assim identificá-lo como uma tradução. Contudo, os inúmeros acréscimos - que triplicam o tamanho do texto - e a inclusão de novas personagens indicam claramente que o texto não foi apenas traduzido, mas adaptado. Desse modo, reconhecemos o texto-alvo como uma adaptação interlingual.

Talvez os aspectos mais marcantes dessa adaptação sejam a antropomorfização e a inserção de novas personagens. O Burro, Borrico ou Borriquito do texto-fonte é tratado como burrinho no texto-alvo, mas esse burrinho recebe nome e sobrenome: Zeca Asno. Após ser apresentado na primeira frase da fábula (Zeca era um burrinho que vivia na saída da cidade, pertinho do bosque), o protagonista passa a ser chamado sempre de Zeca. Apenas no final da história surge seu sobrenome ("Vaidoso, Zeca mandou colocar uma placa bem em frente de sua casa: Zeca Asno - Músico”). A primeira ilustração, contudo, dá conta de apresentar seu sobrenome desde o início, já que adorna a porta da casa do burrinho com uma placa onde se lê "Sr. Asno". O aspecto antropomorfizado também é marcante nas ilustrações: o burrinho anda sobre duas patas, usa roupas e chapéu, mora em uma casa e é capaz de usar suas mãos para segurar objetos. Possivelmente, o intuito dessas adaptações é aumentar a identificação da criança com a personagem. 
O Zagal que esqueceu a flauta no texto de partida é retextualizado de forma semelhante no texto de chegada: "[...] Zeca pisou em uma flauta que algum pastor havia esquecido”. Essa é a única menção à personagem, que perde a inicial maiúscula e também a conotação de juventude - já que um zagal é um pastor jovem, mas um pastor pode ter qualquer idade. Essa personagem, portanto, mantém seu papel circunstancial na narrativa.

Em contrapartida, surgem novas personagens. A principal delas é o ratinho Tato, amigo de Zeca, com quem o protagonista interage após haver tocado a flauta ("No caminho, encontrou Tato, o ratinho seu amigo: / — Você já sabe que eu sou um grande músico? Esta manhã, no bosque, toquei uma música lindíssima na flauta! / — Que fantástico! — disse Tato, admirado”). Uma ilustração que representa o ratinho em diálogo com o burrinho retrata ambos com características antropomorfizadas, como postura ereta e vestimentas.

Figura 5 - Ilustrações da fábula “O Asno Flautista” [s.d.]
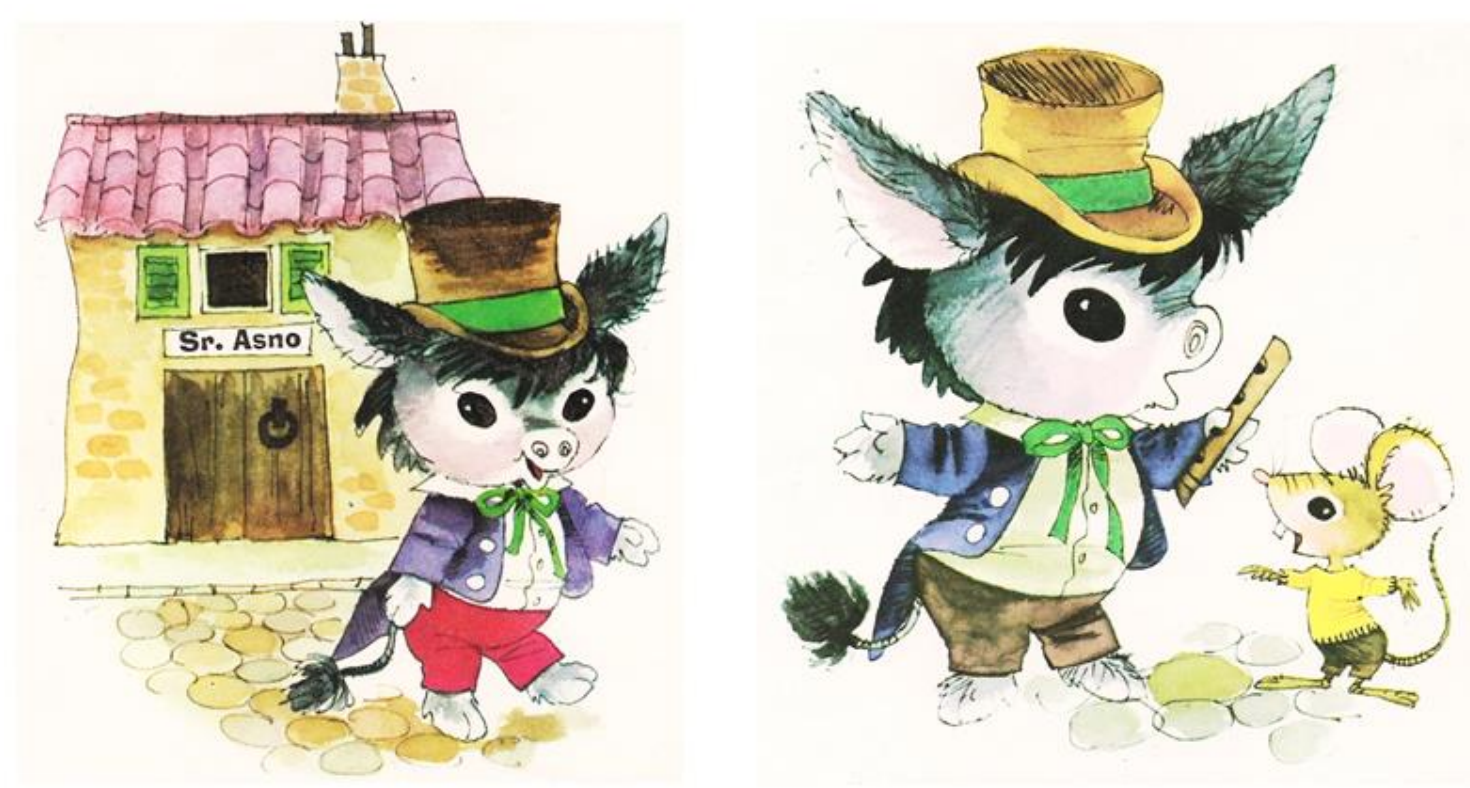

Fonte: Iriarte, [s.d.], p. 2 e p. 7.

Além de Tato, o narrador menciona, implicitamente, os concidadãos de Zeca, ao dizer que após a notícia espalhar-se pela cidade todos se convenceram ("E a notícia correu pela cidade. Ninguém havia ouvido Zeca tocar flauta, mas como ele afirmava que era um gênio musical, todos acabaram se convencendo: - Temos um grande músico!”). Uma ilustração trata de representar parte dessa personagem coletiva, retratando uma gata de vestido, avental e touca, um pato de camisa e chapéu e uma ratinha de vestido e avental. O grupo aparece posicionado em frente a 
duas casas muito parecidas com a do burrinho e localizadas em uma rua pavimentada com o mesmo material da dele, indicando que fazem parte da mesma vizinhança.

A função das novas personagens parece ser o de inflar ainda mais o ego do burrinho, já orgulhoso pelo feito realizado, até chegar ao ponto de este intitular-se músico e trocar a plaquinha de sua porta, de modo a incluir o novo título. E, sobre esse tema, percebemos que também aqui a vaidade é mencionada: pelo som que produziu casualmente na flauta, o burro ficou cheio de si, orgulhoso e vaidoso ("regressou para a cidade, todo orgulhoso e cheio de si / Vaidoso, Zeca mandou colocar uma placa bem em frente de sua casa: Zeca Asno - Músico"). Ou seja, com a utilização de sinônimos, a vaidade é mencionada três vezes, o que faz com que também nessa adaptação tal qualidade seja evidenciada.

As adjetivações vão para além das que lhe atribui o narrador, que o qualifica tanto positiva quanto negativamente: segundo o narrador, o burrinho é alegre, distraído, curioso, orgulhoso, cheio de si e vaidoso. O próprio burro se denomina sempre positivamente: se diz um grande músico e um gênio musical - o primeiro caso, em discurso direto ("— Você já sabe que eu sou um grande músico?"), e o segundo, em discurso indireto ("Ninguém havia ouvido Zeca tocar flauta, mas como ele afirmava que era um gênio musical, todos acabaram se convencendo"). O "grande músico" é ainda reforçado pela voz dos concidadãos ("- Temos um grande músico!"). Tato, o ratinho amigo, recebe do narrador o adjetivo “admirado". Todas as qualificações podem ser vistas como acréscimos, já que o texto de 1782 não conta com qualquer tipo de adjetivação.

A escolha do sobrenome Asno para o burrinho pode ser vista como uma forma de amenizar a qualificação negativa associada à palavra "burro" em português. "Zeca Burro" poderia mais facilmente ser entendido como "Zeca, aquele que é estúpido". Muito embora a palavra "asno" seja também usada com essa conotação negativa, a adjetivação "burro" com essa atribuição de sentido é bem mais difundida. A escolha de "asno" em detrimento de "burro" estende-se até o título da fábula (as formas "asno" e "burro" são sinônimas tanto em português quanto em espanhol).

O espaço é aqui mais bem explorado. São acrescidos trechos descritivos que falam do lugar onde habita o burro (“Zeca era um burrinho que vivia na saída da cidade, pertinho do bosque"), das flores que colhe para enfeitar sua casa ("Vou escolher as mais bonitas para enfeitar a minha casa - dizia alegre, enquanto fazia o buquê”) e do suave canto dos pássaros (“Dois passarinhos conversavam alegremente em cima da flauta, e seus trinados eram tão 
suaves como se fossem música"). Tais trechos apresentam dois ambientes: a cidade, onde vive o burrinho, e o bosque, onde habitam flores e pássaros.

O narrador apresenta o espaço no começo da história e depois o retoma, para dizer que Zeca retornou ("regressou para a cidade, todo orgulhoso e cheio de si") e que sua fama se espalhou ("E a notícia correu pela cidade"). Os acréscimos relativos ao espaço somam em torno de cinquenta palavras e não parecem ter outro propósito que não o de estender um pouco a história, permitindo um maior número de páginas ilustradas.

Na adaptação, verifica-se a inclusão de trechos com propósito claramente educativo, que ressaltam a importância de fazer exercícios ("Todas as manhãs ele saía, bem cedinho, para fazer um pouco de exercício") e se alimentar bem pela manhã ("Depois de tomar um café da manhã bem reforçado, Zeca resolveu colher umas margaridas"), o que soma aproximadamente vinte e duas palavras. Essa adaptação do assunto parece atender à necessidade de um conteúdo doutrinário que estimule a leitor mirim a aceitar determinados comportamentos vistos como saudáveis e adequados para uma criança.

Observamos que a narrativa cresce de forma atípica para fábulas: em geral, a ação das fábulas se dá em uma cena única e curta; contudo, nessa adaptação, o tempo é suficiente para que o burro encontre um amigo ("No caminho, encontrou Tato, o ratinho seu amigo [...]”), para que a notícia de que ele é um grande flautista seja difundida ("E a notícia correu pela cidade. Ninguém havia ouvido Zeca tocar flauta, mas como ele afirmava que era um gênio musical, todos acabaram se convencendo [...]") e para que ele encomende uma placa para sua porta, identificando-se como músico ("Vaidoso, Zeca mandou colocar uma placa bem em frente de sua casa: Zeca Asno - Músico"). Esses acréscimos somam cento e quatro palavras. Com a expansão da história, o narrador ganha mais voz, triplicando sua participação. Ainda assim, proporcionalmente, mantém-se a distribuição de vozes da fábula de 1782.

Em sua maior parte, as falas do burro são introduzidas por verbos de dictum, anunciados pelo narrador: dizer (“dizia alegre”), perguntar-se ("perguntou-se Zeca”), exclamar (“exclamou Zeca"). Em outro momento, o narrador descreve a situação sem introduzir a fala do burro com um verbo de dictum ("No caminho, encontrou Tato, o ratinho seu amigo: - Você já sabe que eu sou um grande músico?”). Para as demais personagens, as falas acontecem de forma semelhante: a voz do ratinho é apresentada pelo verbo dizer (“disse Tato, admirado") e a voz dos cidadãos é introduzida apenas com a descrição da situação ("Ninguém havia ouvido Zeca tocar flauta, mas como ele afirmava que era um gênio musical, todos acabaram se convencendo: — Temos um grande músico!”). 
Quanto aos níveis de linguagem, observamos que a grafia, a sintaxe e o vocabulário são atualizados para a época de publicação, não especificada na edição mas facilmente identificada pelas características gráficas como a segunda metade do século XX. A adaptação parece manter seu vocabulário e suas formulações sintáticas dentro do domínio cognitivo de seu público-alvo, com frases curtas, léxico acessível, uso de voz ativa e discurso direto. Os tipos gráficos são graúdos, como se costuma adotar para leitores iniciantes, e sua fonte assemelha-se a Times New Roman (possivelmente, Verona ou Windsor).

O item lexical "por casualidad', que é repetido a cada estrofe do texto-fonte, aparece no texto-alvo como trechos estendidos, bem explicados, com linguagem simples: “de vez em quando [...] sem motivo nenhum" e "por um acaso, daqueles que também acontecem de vez em quando". Contudo, no final do texto, é traduzido com um nível de linguagem mais elevado pelo uso do pretérito-mais-que-perfeito: “fora apenas um acaso". Essa escolha, apesar de parecer afastar a criança do texto, pode também ser vista como uma oportunidade para o leitor familiarizar-se com estruturas mais elevadas da língua, desde que não se apresente como um obstáculo à leitura - o que não parece ser o caso, mas pode variar conforme a idade e o 68 desenvolvimento cognitivo da criança.

No texto de chegada há, portanto, três formas de retextualizar o "por casualidad', que no texto de partida aparece seis vezes e ainda outra vez na sentença moral, funcionando como tema da composição. Cada uma das formas identificadas no texto de chegada conta com apenas uma ocorrência. $\mathrm{Na}$ sentença moral, apresentada pelo narrador ao final da fábula, integrada ao texto, omite-se a palavra-tema e qualquer outra forma que a traduza ("Quando por uma vez se acerta uma coisa, não quer dizer que saibamos fazê-la bem”), o que tira o destaque da casualidade também na moral. Assim, notamos que, embora o texto-alvo triplique o tamanho do texto-fonte, minimiza o destaque da palavra-tema, que perde força pela variedade de reformulações e pela omissão.

Observando-se as adaptações no texto como um conjunto e analisando seus paratextos, o objetivo geral parece ser aproximar a fábula do público infantil. Para tanto, o adaptador transforma o texto em prosa, oferece mais explicações, antropomorfiza as personagens, inclui ilustrações e aumenta o caráter educativo, que ultrapassa o campo moral e alcança o ideário de um estilo de vida saudável, alheio à obra de Iriarte. Assim, é possível afirmar que o texto-alvo tende para o polo da aceitabilidade. 


\section{Considerações finais}

Observando as adaptações no texto-alvo $O$ asno flautista como um conjunto e analisando seus paratextos, consideramos que o objetivo geral parece ser aproximar a fábula do público infantil, o que fica evidente pelo tipo de ilustrações utilizadas, pela publicação de uma única fábula em um volume pequeno e redigido com letras grandes, pela antropomorfização das personagens e pela reconstrução do texto em prosa com um grande número de acréscimos que tornam o texto mais explicado e educativo. Realiza adaptações que alcançam o texto de forma global, alterando a construção de sentidos em diversos aspectos, como a humanização das personagens, a inclusão de conteúdo educativo referente a hábitos (caminhar, alimentar-se bem, enfeitar a casa com flores), a adição de um novo ambiente, a inserção de novas personagens, a multiplicação do número de cenas, a explicitação do tema da vaidade, as qualificações do protagonista e a omissão da palavra-tema. O caráter educativo do texto-alvo ultrapassa o campo moral e alcança o ideário de um estilo de vida saudável, alheio à obra de Iriarte. Em todos os níveis analisados, o texto-alvo tende para o polo da aceitabilidade e, por suas características dominantes, identificamos essa retextualização como uma adaptação interlingual.

Considerando as características gerais das fábulas, como pouca descrição, assentar-se essencialmente sobre uma ação que é muito fundamentada num diálogo no tempo presente, em uma só unidade de cena, com economia de personagens e uso de personagens animais, observamos que o texto-alvo se comporta de formas semelhantes em alguns aspectos e de formas distintas em outros. O uso de personagens animais e os diálogos em tempo presente são mantidos, mas a cena única e a economia de personagens encontram desvios com a inclusão de novas cenas e novas personagens. Quanto à pouca descrição, observou-se que o texto-alvo inclui acréscimos relativos às personagens, ao espaço e a outros temas, como vida saudável. Em todos os aspectos nos quais se verifica mudança, o público-alvo infantil parece exercer papel fundamental.

Tendo em conta os padrões literários de cada época, como o uso de versos na literatura - considerando que a forma poética foi durante muito tempo o modo de expressão literário por excelência, e era, portanto, frequente que a produção literária ocorresse em verso -, a retextualização analisada acompanha e demonstra a evolução do gênero "fábula", que nos últimos séculos tende a se configurar no formato de prosa. Ao que parece, essa tendência tanto se dirige ao propósito de se aproximar mais do público-alvo infantil quanto se relaciona com a evolução da própria literatura a partir da consolidação da imprensa, que tornou dispensável o uso de recursos mnemônicos voltados para a permanência da literatura na oralidade, como era o caso do verso rimado e metrificado. 
A adaptação analisada marca a presença de Iriarte no Brasil, colocando-o lado a lado com outros grandes fabulistas, o que denota sua relevância no cenário mundial como autor de fábulas. Contudo, apresenta ao público brasileiro uma versão bem diferente da fábula composta pelo autor espanhol, que era centrado na forma poética e nos assuntos da literatura - não é à toa que seu fabulário se chama Fábulas Literárias, posto que tem aplicação especial na literatura e refere-se a escritores, tradutores, obras, citações, etc. "El burro flautista" tem uma aplicação mais abrangente, mas em sua maioria as fábulas de Iriarte são bem restritas ao mundo literário. A adaptação transforma o texto-alvo de modo a deixá-lo mais atrativo e apropriado para o público infantil e se afasta das características formais e estilísticas do texto-fonte, que possivelmente só fariam sentido hoje em uma tradução voltada para o público adulto e, em particular, para os amantes das letras e atores do universo literário.

\section{REFERÊNCIAS}

BASTIN, Georges L. Adaptation. In: BAKER, Mona; SALDANHA, Gabriela (org.).

Routledge Encyclopedia of Translation Studies. 2. ed. London/New York: Routledge, 2009 [1997]. p. 3-6.

EVEN-ZOHAR, Itamar. The Position of Translated Literature within the Literary Polysystem. In: HOLMES, James; LAMBERT, José; e VAN DEN BROECK, Raymond (org.). Literature and Translation: New Perspectives in Literary Studies. Leuven: Acco, 1978. p. 117-127.

GANCHO, Cândida Vilares. Como analisar narrativas. São Paulo: 2002.

GENETTE, Gérard. Paratextos editoriais. Traduzido por: Álvaro Faleiros. São Paulo: Ateliê, 2009. Tradução de: Seuils [1987].

IRIARTE, Tomás de. Fábulas: O asno flautista. Traduzido por: desconhecido. Belo Horizonte: Villa Rica, [s.d.]. (Coleção Fábulas do Mundo Todo, vol. 16).

LAMBERT, José; VAN GORP, Hendrik. Sobre a descrição de traduções. Traduzido por: Marie-Hélène Catherine Torres e Lincoln Paulo Fernandes. In: GUERINI, Andrea; TORRES, Marie-Hélène Catherine e COSTA, Walter Carlos (org.). Literatura e tradução: textos selecionados de José Lambert. Rio de Janeiro: 7Letras, 2011. p. 208-223. Tradução de: On describing translations [1985].

MOISÉS, Massaud. Dicionário de termos literários. 12. ed. rev. e ampl. São Paulo: Cultrix, 2004.

QUILIS, Antonio. Métrica española. Madrid: Alcalá, 1975.

ROSAS, Clarissa. As fábulas de Tomás de Iriarte ao longo do tempo: um estudo descritivo de retextualizações em português e espanhol. Orientadora: Cintrão, H. 2017. 277 f.

Dissertação (Mestrado em Estudos da Tradução) - Faculdade de Filosofia, Letras e Ciências 
Humanas, USP, São Paulo, 2017. Disponível em:

http://www.teses.usp.br/teses/disponiveis/8/8160/tde-09082018-143111/pt-br.php. Acesso em: set. 2019.

ROSAS, Clarissa. Tradução e adaptação na literatura infantojuvenil: o gênero fábula. Revista de Estudos Universitários - REU, v. 42, n. 1, p. 175-197, ago. 2016. Disponível em: http://periodicos.uniso.br/ojs/index.php/reu/article/view/2475. Acesso em: dez. 2019.

ROSAS, Clarissa; CINTRÃO, Heloísa Pezza. A retextualização intralingual de fábulas: um estudo de caso. Tradterm, v. 32, p. 164-189, dez. 2018. Disponível em: http://www.revistas.usp.br/tradterm/article/view/151249. Acesso em: dez. 2019.

TERREROS Y PANDO, Esteban de. Diccionario castellano con las voces de ciencias y artes y sus correspondientes en las tres lenguas francesa, latina e italiana. Tomo primero. Madrid: Imp. Viuda de Ibarra, 1786. Disponível em: ntlle.rae.es/ntlle/SrvltGUISalirNtlle. Acesso em: dez. 2019.

TOURY, Gideon. Descriptive Translation Studies and Beyond. Amsterdam-Philadelphia: Benjamins, 1980.

VINAY, Jean-Paul; DARBELNET, Jean. Stylistique comparée du français et de l'anglais. Paris: Didier, 1958.

YRIARTE, D. Tomas de. El Burro Flautista. In: Fábulas Literarias. Madrid: Imprenta Real, 1782. Disponível em: https://books.google.com.br/books?id=9IItTLv-

$\mathrm{X} 2 \mathrm{gC} \&$ printsec $=$ frontcover\&hl $=\mathrm{pt}-$

BR\&source=gbs_ge_summary_r\&cad=0\#v=onepage\&q\&f=false. Acesso em: dez. 2019.

ZILBERMAN, Regina. A Literatura Infantil na Escola. 11. ed. São Paulo: Global, 2003.

\footnotetext{
* Clarissa ROSAS - Doutoranda em Letras na Universidade Federal da Paraíba. Mestra em Letras (2017) pela Universidade de São Paulo. Graduada em Tradução (2013) e Arquitetura e Urbanismo (2009) pela Universidade Federal da Paraíba. João Pessoa, Paraíba, Brasil.

Currículo acadêmico: http://lattes.cnpq.br/3031983029827104

ORCID: https://orcid.org/0000-0001-8119-8159

E-mail: rosas.trad@gmail.com

1 Disponível em: https://books.google.com.br/books?id=NfpFAAAAcAAJ\&printsec=frontcover\&hl=pt$\mathrm{BR} \&$ source $=\mathrm{gbs} \_g e \_s u m m a r y \_r \& c a d=0 \# \mathrm{v}=$ onepage $\& \mathrm{q} \& \mathrm{f}=$ false. Acesso em: dez. 2019.

${ }^{2} \mathrm{Na}$ contagem de sílabas em castelhano, acrescenta-se uma sílaba quando o verso termina em palavra oxítona ou em monossílabo tônico.

3 Ao falar de "arcaísmos", adotamos a perspectiva de um leitor de 2019, tendo claro que, na época de publicação, a palavra não se aplicaria. "Arcaísmos" está sendo usado, portanto, no sentido de marcas de distância temporal percebidas no texto, da perspectiva atual.
} 